\title{
IN SITU CROSSLINKING OF CHLOROPHYLL TO PROTEIN. USE OF SPECIFIC HETEROBIFUNCTIONAL PHOTOACTIVATED REAGENTS
}

\author{
by \\ URSULA G. HINZ \\ Department of Physiology, Carlsberg Laboratory, \\ Gamle Carlsberg Vej 10, DK-2500 Copenhagen Valby \\ Present address: Friedrich Miescher Institut, \\ P.O. Box 2543, CH-4002 Basel, Switzerland
}

Keywords: Chlorophyll organization, light-harvesting complex, photosystem II

It is shown that reagents containing one reactive amino group and one azide group crosslink chlorophyll to protein in situ. Using the light-harvesting complex of photosystem II as model system a small fraction of the chlorophyll $a$, but no chlorophyll $b$ was covalently bound to the protein. This confirms that chlorophyll $a$ is more accessible from the medium. 4-Azidoaniline, 4-azido-2-nitroaniline and 2-azido-4-chloroaniline are equally effective crosslinkers and are recommended as probes for the chlorophyll organization in native or reconstituted chlorophyll-protein complexes.

\section{INTRODUCTION}

In higher plants light energy for photosynthesis is captured by pigments that are non-covalently bound in a number of light-harvesting protein complexes. From there it is channeled into the reaction centers. Efficient transfer of excitation energy requires that the pigments are at specific distances and angles relative to each other. To achieve this, the pigments are organized in distinct chlorophyll(Chl)-protein complexes in the thylakoids of the chloroplast.

Treatment of Chl-protein complexes with proteases has shown that practically all the Chl is associated with the membrane-spanning parts of the polypeptides and that the pigments are not directly accessible from the water-phase $(9,20)$. All thylakoid Chl-proteins that have been investigated so far have a very high content of $\alpha$-helices located almost vertical to the plane of the membrane, indicating that the pigments are bound between these helices $(13,14,19,22)$. Predictions of secondary structure, hydrophobicity index and accessibility of various parts of the polypeptide chain have been used to construct models of the transmembrane organization of $\mathrm{P} 700 \mathrm{Chl}_{a}-\mathrm{Pl}$ and the light harvesting

Abbreviations: $\mathrm{Chl}=$ Chlorophyll; $\mathrm{DTT}=$ dithiothreitol; $\mathrm{LHCII}=$ light harvesting complex of photosystem II; PAGE = polyacrylamide gel electrophoresis; $P S=$ photosystem; $S D S=$ sodium dodecylsulfate; TLC = thin-layer chromatography; Tricine $=\mathrm{N}($ tris(hydroxymethyl)methyl)glucine. 
complex of photosystem II (LHCII) $(1,3,4,9$, 10). It has been hypothesized that histidine or glutamine residues are involved in holding the chlorophylls in place, but we still do not know how a protein like LHCII can bind $13 \mathrm{Chl}$ molecules per $25 \mathrm{kD}$ polypeptide. There is no direct evidence which amino acid sidechains or which parts of the polypeptide chain are interacting with the pigments to achieve the superb degree of organization that is found in the Chl-protein complexes.

Herein, I describe a method for binding chlorophyll covalently to the polypeptides. This is a prerequisite for the determination of the environment of the pigment molecules and the identification of the chlorophyll binding sites.

\section{METHODS}

\subsection{Biological preparations}

Wild type barley seedlings (Hordeum vulgare cv Svalöfs Bonus) were grown for seven days in vermiculite under $16 \mathrm{~h}$ light (1700 lux) and $8 \mathrm{~h}$ dark cycles. Grana membranes were prepared as described by Møller and Høu (12). The proteins were solubilized with $1 \%$ dodecyl- $\beta, D$ maltoside and LHCII was isolated by sucrose density gradient centrifugation as described previously (8). Gradient fractions containing LHCII were quickly frozen in liquid nitrogen and stored at $-30^{\circ} \mathrm{C}$. They were thawed immediately before use. Thylakoids for SDS-PAGE were prepared as described by MACHOLD et al. (11).

\subsection{Synthesis of the azides from phenylene diamines}

The reactions were performed under dim red light and the concentrations of the reagents were selected so that on a statistical basis only one of the two amino groups on each molecule is converted to an azide. To test the effect of substitutions on the aromatic ring on solubility and photosensitivity I prepared azido-derivatives of the following diamines: $p$-phenylene diamine, 2-nitro- $p$-phenylene diamine or 4chloro- $o$-phenylene diamine. Suspensions (5.4 mmoles) of the diamines in $8 \mathrm{ml}$ of $2 \mathrm{mM} \mathrm{HCl}$ were stirred on dry ice to keep the temperature below $-10^{\circ} \mathrm{C}$. A solution of 5.7 mmoles $\mathrm{NaNO}_{2}$ in $3 \mathrm{ml} \mathrm{H} \mathrm{H}_{2} \mathrm{O}$ was added dropwise, followed by 8 $\mathrm{ml}$ cold glacial acetic acid. Then 6.1 mmoles $\mathrm{NaN}_{3}$ in $2.5 \mathrm{ml} \mathrm{H}_{2} \mathrm{O}$ were added slowly. Subsequently, the mixture was diluted with $15 \mathrm{ml}$ cold water and stirring was continued for $2 \mathrm{~h}$ at $4{ }^{\circ} \mathrm{C}$. Then water was added to give a final volume of $100 \mathrm{ml}$ and the mixture was left for $16 \mathrm{~h}$ at $4{ }^{\circ} \mathrm{C}$ without stirring. The reaction products - small, needle-shaped crystals - were collected by filtration. They were washed with small volume of ice-cold water and stored wet in the dark at $4{ }^{\circ} \mathrm{C}$.

Substitutions on the ring influence the reactivity of the amino groups. Thus, one expects the following products to be formed preferentially: 4-azidoaniline from $p$-phenylene diamine; 4azido-2-nitroaniline from 2-nitro- $p$-phenylene diamine and 2-azido-4-chloroaniline from 4chloro- $o$-phenylene diamine.

\subsection{Reaction with $\mathrm{Chl} a$}

A saturated solution of each azide was made in buffered acetonitrile ( $90 \%$ acetonitrile, $10 \% 1$ $\left.\mathrm{M} \mathrm{NaHCO}_{3} \mathrm{pH} 9.0\right)$. An aliquot $(20 \mu \mathrm{l})$ of each was mixed with $25 \mu \mathrm{g}$ Chl $a$ (Sigma) in $25 \mu \mathrm{l}$ acetonitrile. Oxygen was displaced by a stream of argon and the mixture was incubated under an argon atmosphere for $24 \mathrm{~h}$ in the dark at room temperature. As a control, pure Chl $a$ was incubated under the same conditions. The reaction products were analysed by thin-layer chromotography under dim light, using precoated reverse-phase $\mathrm{C}-18$ silica plates (Whatman) and a solvent composed of methanol:ethylacetate:water $=40: 50: 10$ as described by HENRY et al. (7). Spots containing Chl or its derivatives were scraped off with a razor blade. The pigments were eluted with ethanol and their absorption spectra were recorded on an Aminco DW2a spectrophotometer.

\subsection{Crosslinking of $\mathrm{Chl}$ and proteins}

Thylakoid or grana membranes were resuspended in $1 \%$ dodecyl- $\beta, D-$ maltoside, $100 \mathrm{~mm}$ $\mathrm{NaHCO}_{3} \mathrm{pH} 9.0$ to give ca $0.25 \mathrm{mg} \mathrm{Chl} \cdot \mathrm{ml}^{-1}$ and stored on ice. The detergent was included to solubilize slowly the membranes and thereby 
facilitate the interaction with the crosslinker, whilst the low temperature and the slightly alkaline buffer helped to stabilize the Chlprotein complexes. An aliquot $(40 \mu \mathrm{l})$ of a saturated solution of 4-azidoaniline, 4-azido-2nitroaniline or 2-azido-4-chloroaniline in buffered acetonitrile $(90 \%$ acetonitrile, $10 \% 1 \mathrm{M}$ $\mathrm{NaHCO}_{3} \mathrm{pH} 9.0$ ) was added to $1 \mathrm{ml}$ sample and the mixture was incubated in the dark at $4^{\circ} \mathrm{C}$ for 24 or $48 \mathrm{~h}$.

Alternatively, purified LHCII $(0.25 \mathrm{mg}$ $\mathrm{Chl} \cdot \mathrm{ml}^{-1}$ ) in $0.025 \%$ Triton $\mathrm{X}-100,10 \mathrm{mM}$ tricine and $100 \mathrm{mM} \mathrm{NaHCO}_{3} \mathrm{pH} 9.0$ was incubated with $40 \mu \mathrm{l}$ of a saturated solution of 4-azidoaniline, 4-azido-2-nitroaniline or 2-azido-4-chloroaniline as described above. In this case no dodecyl- $\beta, D$-maltoside was added. To activate the azide, the samples were illuminated for $10 \mathrm{~min}$ with strong white light in a quartz cuvette with occasional mixing. Sodium dodecyl sulfate (SDS) and dithiothreitol (DTT) were added to give final concentrations of $0.5 \%$ and $5 \mathrm{~mm}$ and the samples were heated in a boiling waterbath for $15 \mathrm{~min}$. Aliquots containing 125

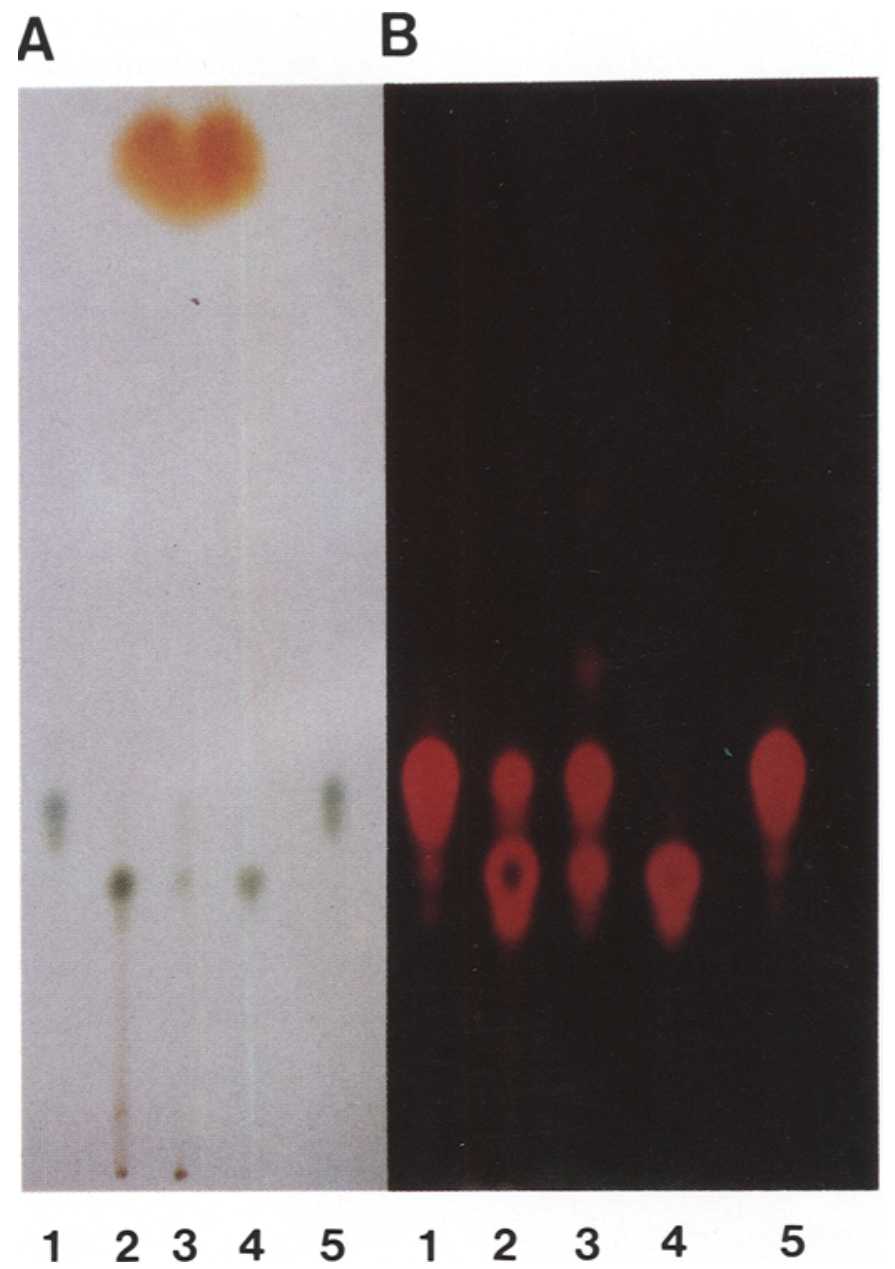

Figure 1. Separation by thin-layer chromatography of $\mathrm{Chl} a$ (lanes 1 and 5) and the derivatives formed after $24 \mathrm{~h}$ incubation with 4-azidoaniline (lane 2), 4-azido-2-nitroaniline (lane 3) or 2-azido-4-chloroaniline (lane 4). Panel $A$ and $B$ show the same plate photographed with visible light and $U V$ light, respectively.

Aliquots were applied to a pre-coated C18 reversed phase silica thin-layer plate and developed using ethyl acetate:methanol:water $=50: 40: 10$ as mobile phase. 


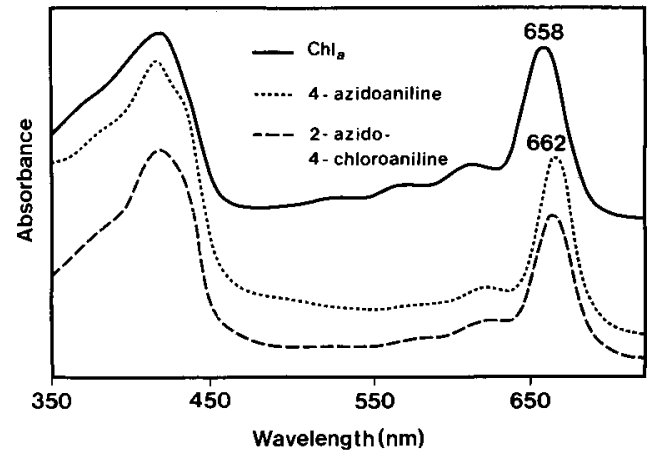

Figure 2. Absorption spectra of Chl $a$ and its derivatives obtained after reaction with 4-azidoaniline, 4-azido-2-nitroaniline or 2-azido-4-chloroaniline. The compounds were eluted from thin-layer plates.

$\mu \mathrm{g}$ Chl were applied for SDS-PAGE on gels containing $6 \mathrm{M}$ urea (16). Covalently bound $\mathrm{Chl}$ was detected by its fluorescence under UV light. In some cases the fluorescent bands corresponding to LHCII or its proteolytic fragments were excised from the urea gel, the gel slices were crushed and the protein was eluted with 5 volumes of $\mathrm{H}_{2} \mathrm{O}$ and then with $0.05 \%$ SDS in 100 mм $\mathrm{NaHCO}_{3} \mathrm{pH}$ 9.0. The eluted material was lyophilized, resuspended in a small volume buffer containing $0.5 \% \mathrm{SDS}, 5 \mathrm{mM}$ DTT and heated again in a boiling waterbath before reapplying it to a urea gel.

\section{RESULTS}

\subsection{Preparation of the crosslinking reagents} and their reaction with $\mathrm{Chl} a$

Chl has a keto-group on ring $\mathrm{V}$ that reacts readily with basic amines (21). Indeed, when Chl $a$ was incubated with $p$-phenylene diamine on the bench top for $24 \mathrm{~h}$ in the dark and under an argon atmosphere it was converted to a product with lower mobility on reversed phase thin-layer chromatography (TLC). Therefore, azide derivatives of $p$-phenylene diamine, 2-nitro- $p$ -

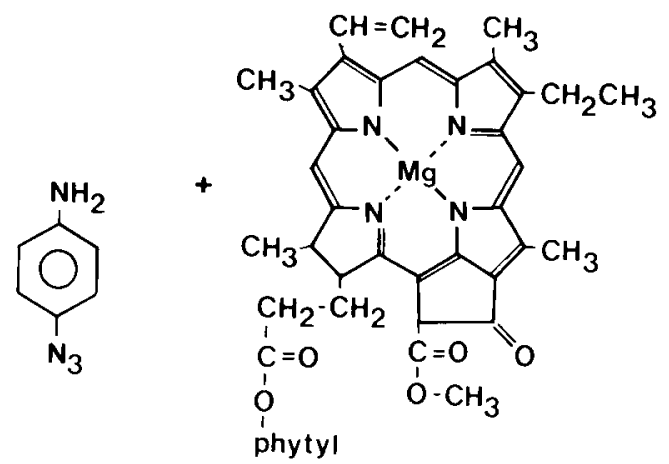

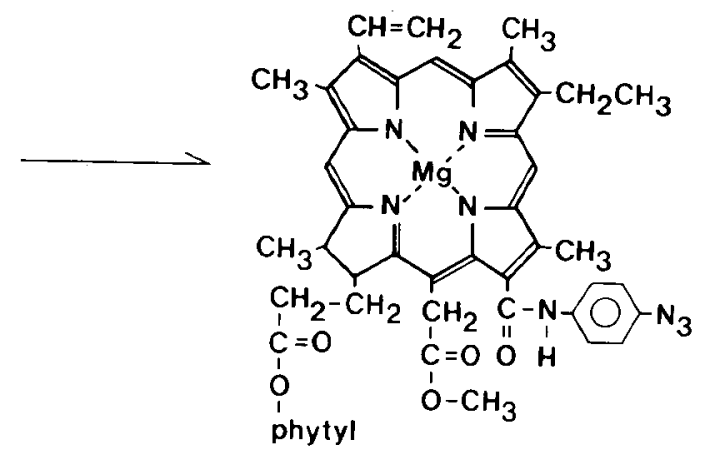

\section{chlorophyll a}

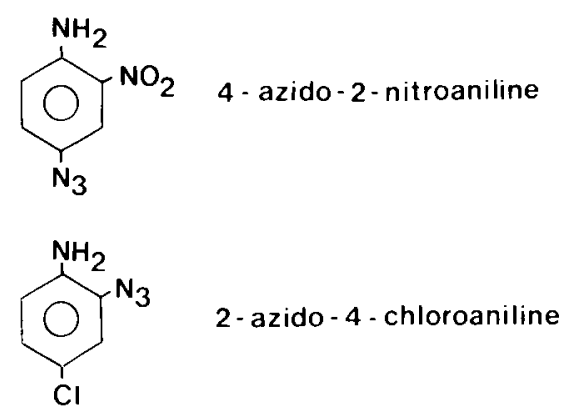

Figure 3. Proposed structure of the $\mathrm{Chl} a$ derivative formed with 4-azidoaniline. The formulae of the other two azidoanilines studied are also given. 
phenylene diamine and 4-chloro-o-phenylene diamine were prepared. Adjusting the conditions so that on a statistical basis only one amino group on each molecule reacted, gave the following products: 4-azidoaniline, 4-azido-2-nitroaniline and 2-azido-4-chloroaniline. All three compounds had pronounced absorption maxima at $252 \mathrm{~nm}$ which decreased when the reagents were exposed to strong white light, which is typical for azides. After $10 \mathrm{~min}$ illumination, the absorbance at $252 \mathrm{~nm}$ did not decrease further. The reagents had broad adsorption maxima in the visible range plus additional minor maxima at $352 \mathrm{~nm}$ (4-azidoaniline) and at $361 \mathrm{~nm}$ (4-azido-2-nitroaniline) which disappeared completely upon illumination.

When Chl $a$ (Sigma) was incubated for $24 \mathrm{~h}$ with the three azidoanilines in the dark and under an argon atmosphere it was converted to a form with lower mobility on reversed phase TLC (Fig. 1). After this period the reaction had almost gone to completion. The reaction products still had the pink Chl fluorescence, but the absorption maxima were shifted to $662 \mathrm{~nm}$ from $658 \mathrm{~nm}$ for unreacted $\mathrm{Chl} a$ (Fig. 2). The proposed structure of the $\mathrm{Chl}$ derivative after reaction with 4-azidoaniline is shown in Figure 3.

\subsection{Covalent binding of $\mathrm{Chl}$ to protein}

Initially, grana or thylakoid membranes were used for crosslinking experiments. Samples were incubated 24 or $48 \mathrm{~h}$ with 4 -azidoaniline, 4-azido-2-nitroaniline or 2-azido-4-chloroaniline in the dark before activation of the azido-groups by strong white light. Then the samples were analysed by SDS-PAGE under denaturing conditions (Fig. 4A and C). In control samples, all the Chl migrated with the free pigment at the front. In crosslinked samples LHCII was most strongly labelled with $\mathrm{Chl}$, but there were also faint bands at the position of other Chl proteins from photosystem II. In addition, there was a fluorescent band below LHCII, where normally no green band is observed. This may be due to proteolytic breakdown products.

To simplify the interpretation of the gel pattern and because it was the most strongly labelled band, isolated LHCII was chosen as a model system. The outcome of one crosslinking experiment is shown in Figure 4B. Most of the Chl still migrated with the free pigment, suggesting that not all $\mathrm{Chl}$ molecules were equally accessible to the crosslinker. When the band corresponding to LHCII was excised and the material was applied to electrophoresis in a second urea containing gel, all the pigment comigrated with LHCII polypeptides and there was no detectable free Chl (Fig. 4D).

Absorption spectra of LHCII eluted from SDS polyacrylamide gels after crosslinking exhibited a single absorption maximum in the red at 662 $\mathrm{nm}$, the same wavelength as the Chl $a$ derivatives, suggesting that only $\mathrm{Chl} a$ had reacted with the crosslinker (Fig. 5). This is in agreement with previous findings indicating that $\mathrm{Chl} a$ is much more accessible from the medium than $\mathrm{Chl} b$. It was not possible to quantitate the amounts of Chl that was covalently bound to the protein, but clearly only a small fraction of the $\mathrm{Chl}$ molecules had reacted, either due to steric hindrance or because only a small subset of peripherally located $\mathrm{Chl} a$ was accessible to the reagents.

\section{DISCUSSION}

The identification of the Chl-binding sites of Chl-proteins from higher plants is seriously hindered by the fact that the pigments are bound to the proteins by non-covalent interactions. Crystals have been obtained of reaction center complexes from several photosynthetic bacteria, and their three-dimensional structure has been determined so that the orientation of the reaction center pigments is known, but it is still not certain with which amino acid residues they interact $(2,5)$. For thylakoid proteins from higher plants, there are so far no satisfactory three-dimensional crystals available. Therefore, it is proposed to analyse the environment and the organization of the $\mathrm{Chl}$ molecules in thylakoid proteins by crosslinking the $\mathrm{Chl}$ to the protein, digesting the polypeptide chain with proteases and determining the amino acid sequence of the fragments labelled with $\mathrm{Chl}$.

A good crosslinking reagent has to fulfil several conditions. It should react specifically with 
U.G. HINZ; Crosslinking chlorophyll to protein
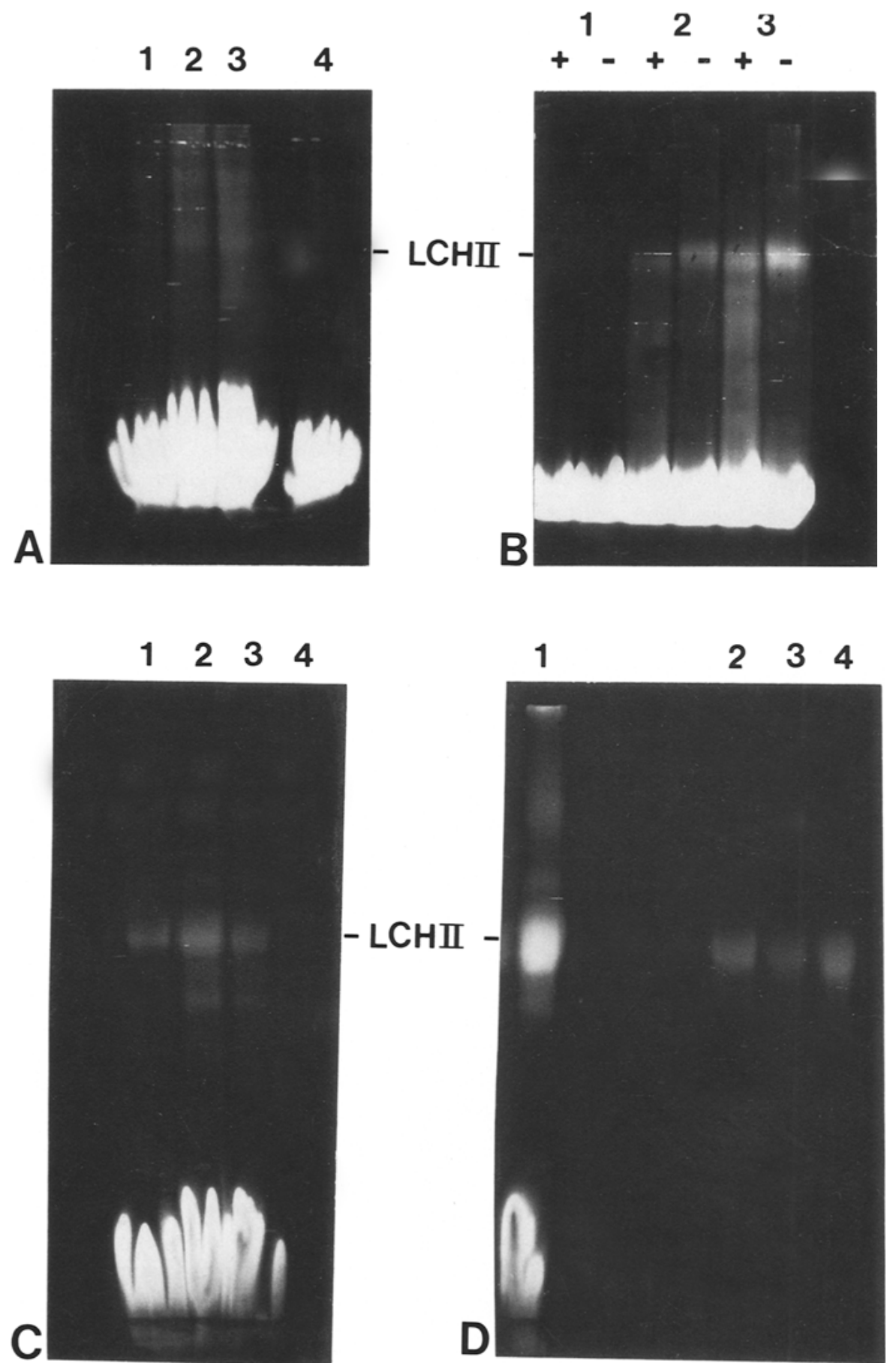
Chl, but the reaction with the polypeptide chain should be as unspecific as possible. This condition is met by azide derivatives of aromatic diamines. Chl has a keto-group on ring $\mathrm{V}$ that reacts with basic amines $(21)$. The reaction proceeds at low temperature and at $\mathrm{pH}$ values where Chl-proteins are not denatured. Considering that the $\mathrm{Chl}$ is not directly accessible from the water phase, the reagents should be amphiphilic, i.e. they should be somewhat water soluble, but lipophilic enough to diffuse into the thylakoid membrane, and they should be small, to be able to get into Chl-binding pockets or folds to reach $\mathrm{Chl}$ that is bound between subunits of Chl-protein complexes. Based on these considerations azido-derivatives of the following compounds were prepared: $p$-phenylene diamine, 2-nitro- $p$-phenylene diamine or 4-chloro- $o$ phenylene diamine. The products 4-azidoaniline, 4-azido-2-nitroaniline and 2-azido-4chloroaniline reacted readily with $\mathrm{Chl} a$ in the dark, giving rise to products with lower mobility on reversed phase TLC. The reaction products still had the pink Chl fluorescence, but their absorption maxima were shifted by $4 \mathrm{~nm}$ to the red.

When thylakoid or grana membranes were treated with these crosslinkers, only a small part of the $\mathrm{Chl}$ could be covalently bound to the

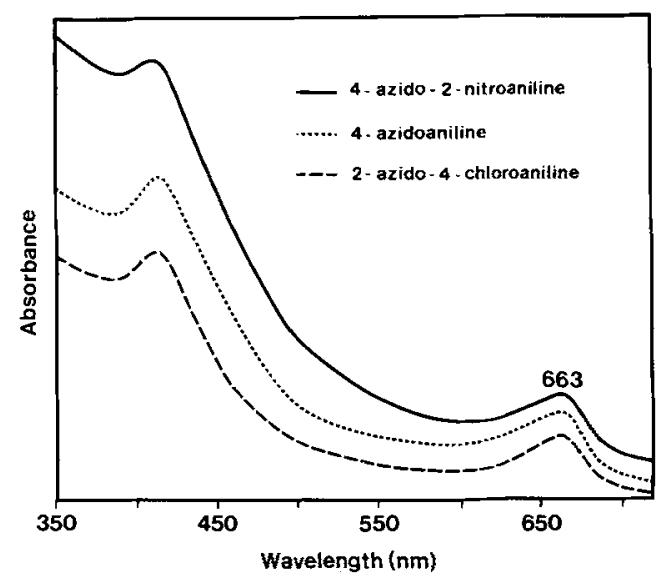

Figure 5. Absorption spectra of LHCII with covalently bound $\mathrm{Chl}$ isolated by SDS-PAGE on gels containing $6 \mathrm{M}$ urea.

proteins. LHCII was the most prominently labelled band, but Chl fluorescence was also detectable at the position of other Chl-proteins. The differential labelling may reflect the relative abundance of the Chl-proteins. About $80 \%$ of the $\mathrm{Chl}$ present in grana membranes is associated with LHCII. The amount of Chl bound did not change when the incubation time was varied between 24 and $48 \mathrm{~h}$, suggesting that the limiting

Figure 4. Denaturing SDS-PAGE of solubilized thylakoid membranes and purified LHCII after crosslinking with azidoanilines. Aliquots containing ca $125 \mu \mathrm{g} \mathrm{Chl}$ were heated in a boiling waterbath before application to gels containg $6 \mathrm{M}$ urea. The gels were photographed under UV light.

A: Crosslinking of thylakoid membranes using 2-azido-4-chloroaniline (lane 1), 4-azido-2-nitroaniline (lane 2) or 4-azidoaniline (lane 3). Lane 4: control without crosslinker.

B: Crosslinking of purified LHCII. The samples labelled (+) were exposed to $25 \mu \mathrm{g}$ protease V8 for $90 \mathrm{~min}$ at room temperature.

Lane 1) Control

Lane 2) 4-azido-2-nitroaniline

Lane 3) 2-azido-4-chloroaniline

C: Another crosslinking experiment using thylakoid membranes.

Lane 1) 4-azidoaniline

Lane 2) 4-azido-2-nitroaniline

Lane 3) 2-azido-4-chloroaniline

Lane 4) control

D: After crosslinking the LHCII band was excised from an SDS-urea gel, the protein was eluted and reapplied to SDS-PAGE on a gel containing $6 \mathrm{~m}$ urea.

Lane 1) Grana membranes crosslinked with 4-azidoaniline

Lanes 2-4) LHCII after crosslinking with 4-azidoaniline (2), 4-azido-2-nitroaniline (3) or 2-azido-4-chloroaniline (4) isolated by denaturing SDS-PAGE. 
factor was the accessibility of the pigments rather than the formation of the Schiff base. Similar crosslinking yields were obtained using the three differently substituted azidoanilines. This may be due to excitation transfer to the crosslinker from neighbouring Chl molecules. It has been shown that $\mathrm{Chl}$ and other porphyrins can be used to photosensitize reactions (6).

Experiments with isolated LHCII revealed that only Chl $a$ was bound by the crosslinker, thus confirming that $\mathrm{Chl} a$ is much more accessible from the water phase than Chl $b$. This result, in combination with the low crosslinking yield, indicates that only the outermost layer of Chl was accessible to the crosslinker.

The crosslinking method presented here seems suitable to identify $\mathrm{Chl}$ binding sites of Chl-proteins with known amino acid sequence. At the same time the accessibility of $\mathrm{Chl}$ molecules can be explored and yield information about the three-dimensional structure of Chl-protein complexes. Since it is possible to reconstitute LHCII with pigments (17) a further approach is to react isolated $\mathrm{Chl} a$ and $b$ with the crosslinker in the dark, reconstitute the pigments with the protein and then crosslink the $\mathrm{Chl}$ to the protein. This is expected to give much higher crosslinking yields and permit the identification of Chl-binding domains that are not accessible from the outside.

\section{ACKNOWLEDGEMENTS}

I wish to thank Professor DITER VON WETTSTEIN for his encouragement and support throughout my stay at the Carlsberg Laboratorium and for his critical reading of the manuscript. DAVID SIMPSON is thanked for the many stimulating discussions we had. I am indebted to NINA RASMUSSEN for drawing the figures and to ANN-SOFI STEINHOLTZ and INGE OBERGFOELL for photographic work.

\section{REFERENCES}

1. ANDERSON, J.M. \& D.J. GoODCHILD: Lateral heterogeneity of thylakoid complexes and the transverse arrangement of the light-harvesting chlorophyll $\mathrm{a} / \mathrm{b}$ protein of photosystem II of thylakoid membranes. Chem. Scr. 27B, 181-188 (1987)
2. Deisenhofer, J., O. EPP, K. Miki, R. Huber \& H. MICHEL: X-ray structure analysis of a membrane protein complex. Electron density map at $3 \AA$ resolution and a model of the chromophores of the photosynthetic reaction center from Rhodopseudomonas viridis. J. Mol. Biol. 180, 385-398 (1984)

3. FISH, L.E., U. KÜCK \& L. BOGORAD: Two partially homologous adjacent light-inducible maize chloroplast polypeptides of the $\mathrm{P} 700 \mathrm{Chl}$-a-protein complex of photosystem I. J. Biol. Chem. 260, 1413-1421 (1985a)

4. FISH, L.E., U. KÜCK \& L. BOGORAD: Analysis of the two partially homologous P700 chlorophyll $a$ proteins of maize photosystem I: predictions based on the primary sequences and features shared by other chlorophyll proteins. In: Molecular Biology of the Photosynthetic Apparatus (Stainback, K.E., S. Bonitz, C.J. Arntzen \& L. Bogorad eds.) Publ.: Cold Spring Harbor Laboratory. pp. 111-120 (1985b)

5. Ford, R.C., D. Picot \& R.M. Garavito: Crystallization of the photosystem I reaction centre. EMBO J. 6, 1581-1586 (1987)

6. FuJimori, E.: Chlorophyll-photosensitized reduction of triphenyltetrazolium chloride by hydrazine hydrate. J. Am. Chem. Soc. 77, 6495-6498 (1955)

7. Henry, L.E.A., J.D. Mikkelsen \& B.L. Møller: Pigment and acyl lipid composition of photosystem I and II vesicles and of photosynthetic mutants in barley. Carlsberg Res. Commun. 48, 131-148 (1983)

8. HINZ, U.G.: Isolation of the photosystem II reaction center complex from barley. Characterization by circular dichroism spectroscopy and amino acid sequencing. Carlsberg Res. Commun. 50, 285-298 (1985)

9. HINZ, U.G. \& K.G. WELINDER: The light-harvesting complex of photosystem II in barley. Structure and chlorophyll organization. Carlsberg Res. Commun. 52, 39-54 (1987)

10. Karlin-NeumanN, G.A., B.D. Kohorn, J.P. THORNBER \& E.M. TOBIN: A chlorophyll a/bprotein encoded by a gene containing an intron with characteristics of a transposable element. $J$. Mol. Appl. Genetics 3, 45-61 (1985)

11. Machold, O., D.J. Simpson \& B.L. Møller: Chlorophyll proteins of thylakoids from wild type and mutants of barley (Hordeum vulgare). Carlsberg Res. Commun. 44, 235-254 (1979)

12. Møller, B.L. \& P.B. Høu: A thylakoid polypeptide involved in the reconstitution of photosynthetic oxygen evolution. Carlsberg Res. Commun. 48, 161-185 (1983)

13. Nabedryk, E., P. Biaudet, S. Darr, C.J. ARnTzen \& J. BRETON: Conformation and orientation of 
Chl-proteins in photosystem I by circular dichroism and polarized infrared spectroscopies. Biochim. Biophys. Acta 767, 640-647 (1984)

14. NABEDRYK, E., S. ANDRIANAMBININTSOA \& J. BRETON: Transmembrane orientation of $\alpha$-helices in the thylakoid membrane and in the light-harvesting complex. A polarized infrared spectroscopy study. Biochim. Biophys. Acta 765, 380-387 (1984)

15. NANBA, O. \& K. SATOH: Isolation of a photosystem II reaction center constisting of D1 and D2 polypeptides and cytochrome b559. Proc. Natl. Acad. Sci. USA 84, 109-112 (1987)

16. Piccioni, R.G.,P. Bennoun \& N.H.Chua: A nuclear mutant of Chlamydomonas reinhardii defective in photosynthetic photophosphorylation. Characterization of the alga coupling factor ATPase. Eur. J. Biochem. 117, 93-102 (1981)

17. Plumley, F.G.\& G.W. SCHMidT: Reconstitution of chlorophyll a/b light-harvesting complexes: Xanthophyll-dependent assembly and energy transfer. Proc. Natl. Acad. Sci. USA 84, 146-150 (1987)
18. Ortiz, W., E. Lam, S. Chollar, D. Munt \& R. MALKIN: Topography of the protein complexes of the chloroplast thylakoid membrane. Studies of photosystem I using a chemical probe and proteolytic digestion. Plant Physiol. 77, 387-397 (1985)

19. SATOH, K: Protein-pigments and photosystem II reaction center. Photochem. Photobiol. 42, 845853 (1985)

20. Siefermann-Harms, D. \& H. Ninneman: Pigment organization in the light-harvesting chlorophyll$\mathrm{a} / \mathrm{b}$ protein complex of lettuce chloroplasts. Evidence obtained from protection of the chlorophylls against proton attack and from excitation engergy transfer. Photochem. Photobiol. 35, 719 731 (1982)

21. Weller, A. \& R. Livingston: The reaction of chlorophyll in amines. J. Am. Chem. Soc. 76, 1575-1578 (1954)

22. ZUBER, H.: Structure and function of light-harvesting complexes and their polypeptides. Photochem. Photobiol. 42, $821-844$ (1985) 